\title{
IN VITRO SIMULATION RESEARCH ON THE HOOP STRESS OF MYOCARDIAL BRIDGE - CORONARY ARTERY
}

\begin{abstract}
An analog device which can simulate myocardium bridge oppresses mural coronary artery is designed. The device can be used to research the dynamic changes of the proximal and distal hoop stresses. Meanwhile, the independent regulation of the hoop stresses is realized. The "myocardial bridge - coronary artery" analog device is built to adjust the external pressure of the simulated coronary artery and the oppression level of the myocardial bridge and to record the changes of the hoop stresses. The In vitro simulation experiment indicate that the anomaly of hoop stress mainly occurs in the proximal end. As the oppression level increases, the mean proximal hoop stress and the oscillatory value (maximum-minimum) increase obviously. The "myocardial bridge - coronary artery" analog device can provide a method to study the influence of the hoop stress on the mural coronary artery in vitro.
\end{abstract}

Hao Ding ${ }^{1,2}$, Kun Shang ${ }^{1,2}$, Lanhai Lian ${ }^{1}$, Lingxi Zhao ${ }^{1}$, Lixing Sheng ${ }^{1,2}$, Yanjun Zeng ${ }^{3 *}$
Russ J Cardiol 2014, 7 (111), Engl.: 51-54

Key words: mural coronary artery, myocardial bridge, hemodynamic, hoop stress.
${ }^{1}$ School of Medical Instrument and Food Engineering, University of Shanghai for Science and Technology, Shanghai; 'Shanghai Medical Instrumentation College, Shanghai; ${ }^{3}$ Biomechanics \& Medical Information Institute, Beijing University of Technology, No. 100 PingLeYuan, Beijing, China.

The work of this project was funded by Shanghai Education Committee scientific research innovation projects (13YZ148) and national project cultivation fund of USST.

Corresponding author. Yanjun Zeng, Tel: +861067391809; e-mail: yjzeng@bjut edu.cn

Received January 30, 2014.

Revision received February 03, 2014.

Accepted February 10, 2014.

\section{IN VITRО ИМИТИРУЮЩЕЕ ИССЛЕДОВАНИЕ КОЛЬЦЕВОГО НАПРЯЖЕНИЯ МИОКАРДИАЛЬНОГО МОСТА - КОРОНАРНОЙ АРТЕРИИ}

\begin{abstract}
Hao Ding ${ }^{1,2}$, Kun Shang ${ }^{1,2}$, Lanhai Lian ${ }^{1}$, Lingxi Zhao ${ }^{1}$, Lixing Sheng
Предложено аналоговое устройство, которое может имитировать угнетение миокардиальным мостом стенки коронарной артерии. Устройство может быть использовано для исследования динамических изменений проксимального и дистального кольцевых напряжений. Между тем, реализуется независимое регулирование кольцевых напряжений. "Миокардиальный мост - коронарная артерия" аналоговое устройство создано для регулировки внешнего давления смоделированной коронарной артерии и угнетение уровня миокардиального моста и для записи изменений кольцевых напряжений. In vitro имитационного эксперимент указывают на то, что аномалия кольцевых стресс возникает в основном в проксимальном конце. По мере того, как уровень угнетения повышается, среднее проксимальное кольцевое напряжение и колебательного значение (максимум-минимум), соответственно, увеличивается. "Миокардиальный мост - коронарная артерия" аналоговое устройство может
\end{abstract}

\section{Introduction}

The normal coronary artery and its branches are usually located under the epicardium. When a section of the coronary artery covered by the superficial myocardium is located in the myocardium, the coronary artery is called mural coronary artery $(\mathrm{MC})$ and the myocardium is called myocardial bridge (MB).

A patient needs treatment when MC stenosis is over $50 \%$. Sometimes the effect of drug therapy is poor for some MB patients and a part of MB patients even cannot tolerate drug therapy, so percutaneous transluminal coronary angioplasty or stent implantation is usually used for them. Coronary artery stent implantation not only can correct the abnormal MC hemodynamic, but also can make the MC blood flow return to normal. However, $10 \%-50 \%$ of the patients may develop stent restenosis after receiving coronary artery stent implantation and even more seriously, the coronary artery rupture may happen in or after the treatment [1-3]. обеспечить метод для изучения влияния кольцевого напряжения на стенки коронарной артерии in vitro.

Российский кардиологический журнал 2014, 7 (111), Англ.: 51-54

Ключевые слова: стенка коронарной артерии, миокардиальный мост, гемодинамика, кольцевое напряжение.

${ }^{1}$ School of Medical Instrument and Food Engineering, University of Shanghai for Science and Technology, Шанхай; ${ }^{2}$ Shanghai Medical Instrumentation College, Шанхай; ${ }^{3}$ Biomechanics \& Medical Information Institute, Beijing University of Technology, No. 100 PingLeYuan, Пекин, Китай.

The hoop stress is one of the important hemodynamic factors. It is the stress along the tangential direction of the artery wall's cross section and it is mainly related to the vascular rupture [4-5]. Therefore, the research on MC hoop stress distribution can help us to prevent the coronary artery rupture in or after stent implantation.

Now, there are some researches on the numerical simulation of the normal artery wall residual strain and stress [6-8].

The strain cavity system can provide tensile stress environment [9], so the normal blood vessels under hoop stress can be simulated in vitro. However, the strain cavity system cannot simulate the hoop stress environment when the MB exists around the coronary artery. So a new device is needed. It should be able to simulate the MB oppressing the coronary artery, acquire the parameters related to the hoop stress, and have durable, repeatable and controllable experimental conditions. 


\section{Methods}

\section{The structure and function of the device}

Figure 1 is the block diagram of the "myocardial bridge - coronary artery" analog device structure. The air compressor can inflate and the gas moves into the gasholder to make the pressure stable. The pressure sensor is set at the top of the gasholder to measure the internal pressure. Then the gas flows through proportional pressure valve, and eventually enters into the closed 3-D flow control chamber, so it can provide external pressure for tubular elastic cavity, change the external wall pressure, and regulate the hoop stress. When the internal pressure of the gasholder rises to $30 \mathrm{kPa}$, the air compressor will stop inflating. When the internal pressure of the 3-D flow control chamber is lower than the set value, the gas stored in gasholder will keep on entering into the 3-D flow control chamber through the proportional pressure valve. When the internal pressure of the 3-D flow control chamber is higher than the set value, the gasholder will stop supplying the gas and the proportional pressure valve will be opened to release the gas so as to realize the decompression. The drive motor can drive the MB blocks to oppress the tubular elastic cavity.

Figure 2 is the map of the 3-D flow control chamber. The chamber is a closed organic glass cube and the internal situation can be observed clearly. The size of the internal chamberis $125 \mathrm{~mm} \times 110 \mathrm{~mm} \times 55 \mathrm{~mm}$ (length $\times$ width $\times$ height $)$. The volume of the 3-D flow control chamber is much larger than that of the simulated coronary artery. The device can simulate the coronary artery with $4 \sim 5 \mathrm{~mm}$ inner diameter and $80 \mathrm{~mm}$ length. Measuring point 1 is set at the position where the fluid flows in order to measure the proximal pressure while measuring point 2 is set at the position where the fluid flows out to measure the distal pressure. The MB blocks are set at the both radial sides of the simulated MC. The blocks, which are driven by a motor, conduct the straight reciprocating motion along the guide rail according to the preset depth to oppress the simulated MC. Bilateral or unilateral compression and different sizes' blocks can be chosen to meet the experimental requirement.

\section{Theoretical basis}

The hoop stress of the circular tube can be obtained through the following equation [10]:

$$
\sigma_{\theta}=\frac{\frac{r_{0}{ }^{2}}{r^{2}}+1}{\frac{r_{0}{ }^{2}}{r_{i}{ }^{2}}-1} q_{1}-\frac{1+\frac{r^{2}{ }_{i}}{r^{2}}}{1-\frac{r_{i}{ }^{2}}{r_{0}{ }^{2}}} q_{2}
$$

where $\sigma_{\theta} \sigma_{\theta}$ is the hoop stress of the wall, $\mathrm{q}_{1} \mathrm{q}_{1}$ is the internal wall pressure, $\mathrm{q}_{2} \mathrm{q}_{2}$ is the external wall pressure, $r_{0}$ is the external radius under the load, $r_{i}$ is the internal radius under the load, and $r$ is the radius at any place under the load.

To calculate the internal wall hoop stress, we set $r$ to be $r_{i}$. In real, the radius $r_{0}$ and $r_{i}$ of the elastic tube are

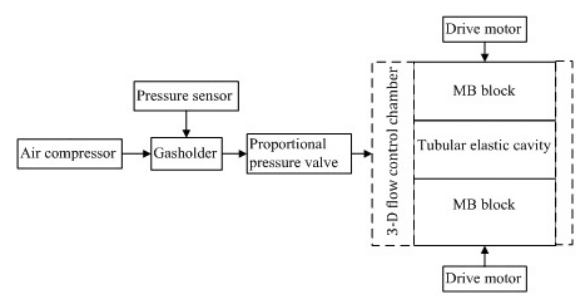

Fig. 1. Block diagram of the "myocardial bridge- coronary artery" analog device structure.

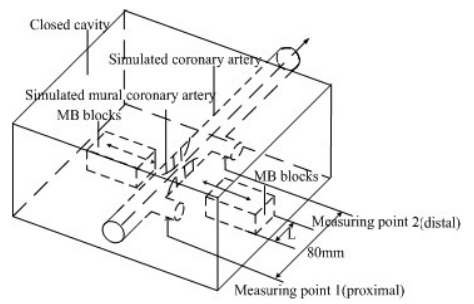

Fig. 2. The map of three-dimensional flow control chamber

influenced by the pressure wave. Therefore, to obtain the geometrical and mechanical characteristics of the silicone tube flow chamber under the impulse, we use the pressure sensor and the parallel light camera to measure the pressure wave and the external radius wave of the silicone tube flow chamber, respectively. By fitting the pressure wave and the external radius wave, we find that the external radius is the monotone function of pressure,

$$
d=a+b \times p+c \times p^{2}-d \times p^{3}+e \times p^{4}
$$

where $d$ is the external diameter of the silicone tube under the load, $p$ is the pressure of the silicone tube flow chamber, and the other parameters are

$$
\text { a } 4.91 \text { b } 3.17 \times 10^{-3} \text { c } 1.18 \times 10^{-5} \text { d } 4.81 \times 10^{-7} \text { e } 2.39 \times 10^{-9}
$$

Denote the internal and external radii of the silicone tube under the load by $r_{i}(t)$ and $r_{0}(t)$. Denote the initial internal and external radii of the tube by $R_{0}$ and $R_{i}$. Due to the incompressible characteristic of the silicone tube [11], we have

$$
\lambda_{z} \pi\left(r_{0}^{2}(t)-r_{i}^{2}(t)=\pi\left(R_{0}^{2}-R_{i}^{2}\right)\right.
$$

Thus, the relationship between the internal and external radii of the tube under the load is

$$
r_{i}(t)=f\left(r_{0}(t)=\sqrt{r_{0}(t)^{2}-\frac{1}{\lambda_{z}}\left(R_{0}{ }^{2}-R_{i}^{2}\right)}(4)\right.
$$

Since the longitudinal stretch ratio $\lambda_{Z}=1.2$ $R_{0}=2.465 \mathrm{~mm} R_{i}=2.165 \mathrm{~mm}$ we have

$$
\begin{aligned}
& r_{i}(t)=f\left(r_{0}(t)=\sqrt{r_{0}{ }^{2}(t)-\frac{1}{1.2}\left(2.465^{2}-2.165^{2}\right)}=\right. \\
& \sqrt{r_{0}{ }^{2}(t)-1.1575}(5)
\end{aligned}
$$


Then, the hoop stress of the silicone tube flow chamber system under the impulse can be calculated by

$$
\sigma_{\theta}=\frac{2 r_{0}{ }^{2}-1.1575}{1.1575} q_{1}-\frac{2 r_{0}{ }^{2}}{1.1575} q_{2}(6)
$$

\section{Experimental design}

According to the clinical parameters of normal human [12], we set that the systolic blood pressure of coronary artery is $120 \mathrm{mmHg}$, the diastolic pressure is $80 \mathrm{mmHg}$, the mean flux is $205 \mathrm{~mL} / \mathrm{min}$, and the heart rate is $60 \mathrm{~min}^{-1}$. During systole, the myocardial bridge oppresses the mural coronary artery [13-16]. Therefore, in the experiment, the systole has the same frequency with that $\mathrm{MB}$ oppresses MC, and the maximal output pressure and the maximal deflection of MB keep synchronous. The fluid in the tube is a mixture of low molecular dextran and normal saline with a ratio of $3: 1$, whose viscosity is $3.8 \times 10^{-3} \mathrm{~Pa} \cdot \mathrm{S}$ [17].

1) Contrast the MC proximal and distal pressure waves of clinical MB patients with the results of the analog device; 2 ) In the case that the external pressure of coronary artery is constant, change the press situation to observe the changes in the proximal and distal hoop stress; 3) Remove the oppression of $\mathrm{MB}$, and change the external pressure of the tube to observe the changes in the proximal and distal hoop stress.

\section{Pressure wave}

Figure 3 shows the pressure wave of coronary artery in human body [18]. Figure 4 shows the pressure wave of the analog device when the level that $\mathrm{MB}$ oppresses $\mathrm{MC}$ is $100 \%$. It is seen from the two figures that the simulation result have the same characteristic with that in human body, which is called "water hammer" [19].

\section{Proximal and distal hoop stress when MB oppresses MC}

Under normal atmospheric pressure, the MB oppresses $\mathrm{MC}$ on different levels. Based on the measured data, the curves of the mean proximal and distal hoop stresses with different oppression levels are shown in Figure 5. As the oppression level increases, the mean proximal hoop stress increases significantly, while the mean distal hoop stress remains unchanged. The oscillatory value of the proximal hoop stress (maximum-minimum) is obviously higher than that of the distal hoop stress. Moreover, an increase in oppression level leads to an increase in the oscillatory value of proximal hoop stress. (Figure 6)

\section{Independent regulation of hoop stress}

The hoop stresses changing with external pressure of simulated mural coronary artery are shown in Figure 7. The analog device can maintain constant internal pressure $\mathrm{q}_{1}$, flux, and other parameters. Change the external pressure $\mathrm{q}_{2}$ to adjust the value of internal hoop stress. The larger $\mathrm{q}_{2}$ is, the less the hoop stress is.

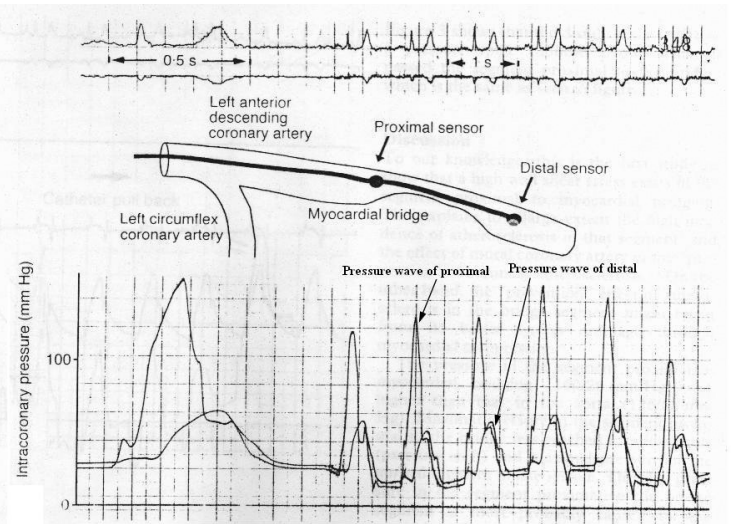

Fig. 3. The proximal and distal pressure wave of mural coronary artery in human body.

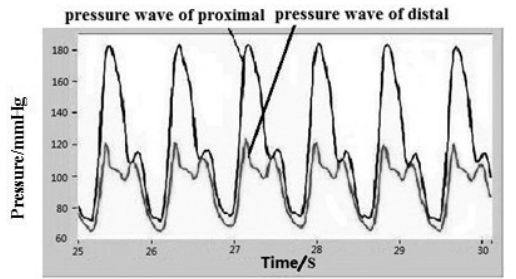

Fig. 4. The proximal and distal pressure wave of mural coronary artery in the analog device.

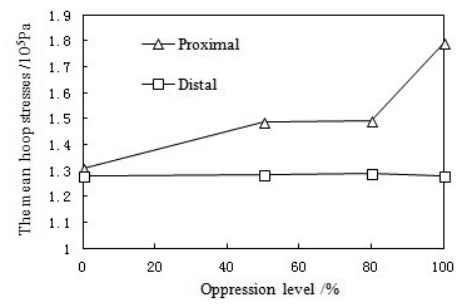

Fig. 5. The mean hoop stresses of the simulated mural coronary artery.

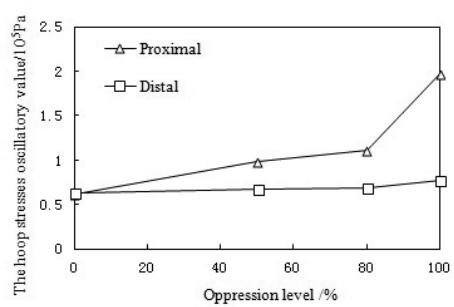

Fig. 6. The hoop stresses oscillatory value of the simulated mural coronary artery.

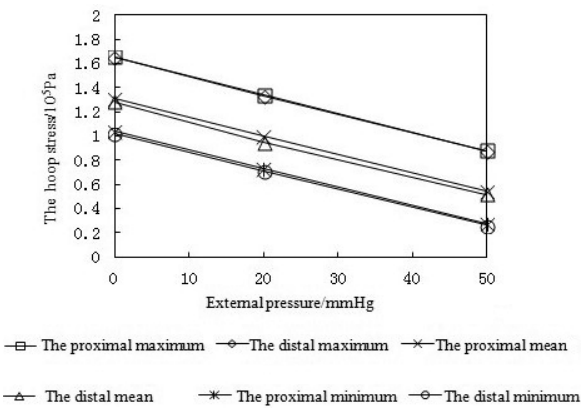

Fig. 7. The hoop stresses changing with external pressure of the simulated mural coronary artery. 


\section{Conclusions and discussion}

Hoop stress plays an important role in the process of the reconstruction of the blood vessels. However, most hemodynamic researches focus on the shear stress at home and aboard nowadays. The reports about the researches on hoop stress are relatively less.

The influence of the abnormal MC proximal hoop stress caused by MB on the coronary artery disease has not been reported and the influence of $\mathrm{MB}$ on the effect of interventional therapy with severe atherosclerosis at proximal MB is not clear [20-22].

The physiological parameters such as blood pressure and blood flow relate to the myocardial bridge coronary artery. It is hard to study the clinical symptoms which caused by a single specific hemodynamic parameter.

In fact, we simulate four situations that $\mathrm{MB}$ oppresses MC. The oppression levels are $0 \%, 50 \%, 80 \%$, and $100 \%$, respectively. As the oppression level increases, the proximal pressure increases gradually, and the distal pressure remains unchanged. The most representative result, i.e., the pressure wave of the $100 \%$ oppression level is shown in this paper. Hypertension and atherosclerosis have reciprocal causation [23-25]. As a result, the increase in the proximal blood pressure caused by MB is closely related with atherosclerotic lesions.

The device in this paper simulates and calculates the proximal and distal hoop stresses of MC. The results indicate that the proximal pressure is much higher than the distal pressure. As a result, the anomaly of hoop stress mainly occurs in the proximal end. As the oppression level

\section{References}

1. Moses JW, Leon MB, Popma JJ, et al. Sirolimus-Eluting Stents versus Standard Stents in Patients with Stenosis in a Native Coronary Artery [J] N Engl J Med 2003; 349:1315-23.

2. Park DW, Park SW, Park KH, et al. Frequency of and risk factors for stent thrombosis after drug-eluting stent implantation during long-term follow-up [J]. Am J Cardiol 2006;98:352-6.

3. McFadden EP, Stabile E, Regar E, et al. Late thrombosis in drug-eluting coronary stents after discontinuation of antiplatelet therapy [J]. Lancet 2004; 364:1519-21.

4. Cheng GC, Loree HM, Kamm RD, et al. Distribution of circumferential stress in ruptured and stable atherosclerotic lesions. A structural analysis with histopathological correlation [J]. Circulation. 1993; 87: 1179-87.

5. Ohayon J, Dubreuil O, Tracqui $P$, et al. Influence of residual stress/strain on the biomechanical stability of vulnerable coronary plaques: potential impact for evaluating the risk of plaque rupture [J]. AJP -Heart and circulatory physiology, 2007, 293 (3): 1987-96.

6. Cardamone L, Valent $n \mathrm{~A}$, Eberth JF, et al. Origin of axial prestretch and residual stress in arteries [J]. Biomechanics and Modeling in Mechanobiology, 2009,8 (6): 431-46.

7. Alastrue V, Pena E, Martinez MA, Doblare M. Assessing the use of the "opening angle method" to enforce residual stresses in patient-specific arteries [J]. Ann Biomed Eng 2007, 35: 1821-37.

8. Azeloglu EU, Albro MB, Thimmappa VA, et al. Heterogeneous transmural proteoglycan distribution provides a mechanism for regulating residual stresses in the aorta [J]. Am J Physiol 2008, 294: 1197-205.

9. Naruse K, Sokabe M. Involvement of stretch-activated ion channels in $\mathrm{Ca} 2+$ mobilization to mechanical stretch in endothelial cells [J]. Am J Physiol, 1993, 264: 797-805.

10. Xu Zhilun. An Introduction to theory of elasticity [M].Beijing: People's Education Press. 1982:87-9.

11. Hu xuqu, Qin kairong, Wu hao, et al. Simulation of arterial pulsatile fluid shear stress and circumferential stress using a silicone tube flow chamber system [J].Journal of Medical Biomechanics, 2006, 21 (2): 94-9.

12. Yao tai, Wu Bowei. Physiology [M]. (sixth edition). Beijin: People's Medical Publishing House, 2003:93-104.

13. Guohui Z, Junbo G. Clinical Analysis of Coronary Myocardial Bridge [J].Chinese Journal of Interventional Cardiology, 2002, 10 (1): 54-6. increases, the mean proximal hoop stress and the oscillatory value (maximum-minimum) increase. The increase in the mean value results in higher risk of the proximal $\mathrm{MC}$ rupture. Meanwhile, as the oscillatory value increases, the proximal end is in the long fatigue load situation, which increases the probability of the rupture.

According to Eq. (6), the proximal and distal hoop stresses are only the functions of the internal pressure $q_{1}$ and the external pressure $q_{2}$. Therefore, we set $q_{1}$ to be constant and change $q_{2}$ to adjust the value of hoop stress. The main aim of this device is not to simulate a particular clinical disease, but to provide an experimental environment, in which the blood pressure, the blood flux, the heart rate, and other physiological parameters are set, and the changes of hoop stress of MB are discussed. Whether the change of the external pressure occurs or not in clinic has not been reported yet.

The increase in the proximal pressure in MC caused by $\mathrm{MB}$ is closely related to the formation of atherosclerosis. The higher mean hoop stress and oscillatory value increase the risk of the blood vascular rupture. The simulation device can provide a method to study the hoop stress of $\mathrm{MC}$ in vitro. In this paper, when $\mathrm{MB}$ presses $\mathrm{MC}$, the changes of internal radii of proximal and distal end are small, which can be ignored. Therefore, we use Eq. (6) to calculate the hoop stress approximately. However, when the internal radii suffer large deformation, Eq. (6) cannot be used to calculate the hoop stress. The method to obtain the hoop stress of MC in this situation will be studied in the future work.

14. Möhlenkamp S, Hort W, Junbo G, et al. Update on Myocardial Bridging [J]. Circulation. 2002, 106: 2616-22

15. Kalaria VG, Koradia N, Breall JA. Myocardial Bridge: a Clinical Review [J]. Catheterization and Cardiovascular Interventions 2002, 57:552-6.

16. Ishii $\mathrm{T}$, Asuwa $\mathrm{N}$, Masuda $\mathrm{S}$, et al. The effects of a myocardial bridge on coronary atherosclerosis and ischaemia [J]. The Journal of Pathology, 1998,185 (1):4-9.

17. Jun $\mathrm{Y}$, Tao G. Study on the normal value of Blood Viscosity [J]. Chinese Journal of Hemorheology, 1998, 8 (1): 69.

18. Junbo G, Erbel R, Görge G, et al. High wall shear stress proximal to myocardial bridging and atherosclerosis: intracoronary ultrasound and pressure measurements [J]. Br Heart J, 1995, 73: 462-5

19. Ding $H$, Chen $Z$, Shen $L$, et al. Heart Pump System in "Heart - Mural coronary artery Myocardial Bridge" Simulative Device [J]. Australasian Physical \& Engineering Sciences in Medicine, 2009, 32 (2): 105-11.

20. Ning-fu W, Pan hao, Tong Guo-xin. The evaluation on stent implantation efficacy of myocardial bridge and severe atherosclerosis lesions in the segments proximal to the myocardial bridge [J].Chinese Journal of Cardiology, 2005, 33 (8): 684-6.

21. Ishikawa $Y$, Akasaka $Y$, Ito $K$, et al. Significance of anatomical properties of myocardial bridge on atherosclerosis evolution in the left anteriordescending coronary artery [J], Atherosclerosis 2006, 186: 380-9.

22. Duygu H, Zoghi M, Nalbantgil S, et al. Myocardial bridge: a bridge to atherosclerosis [J]. Anadolu Kardiyol Derg 2007;7:12-6.

23. Li-song L, Qi H, Bei-lei P. Relationship between coronary atherosclerosis and aortic pulse pressure in patients with primary hypertension [J]. Journal of Clinical Rehabilitative Tissue Engineering Research, 2007, 11 (8): 1567-9.

24. Jankowski P, Kawecka-Jaszcz K, Czarnecka D, et al. Pulsatile but Not Steady Component of Blood Pressure Predicts Cardiovascular Events in Coronary Patients [J]. Hypertension. 2008;51:848-55.

25. Sipahi I, Tuzcu EM, Schoenhagen P, et al. Effects of Normal, Pre-Hypertensive, and Hypertensive Blood Pressure Levels on Progression of Coronary Atherosclerosis [J], J Am Coll Cardiol. 2006;48 (4):833-8. 